\title{
REVIEW
}

\section{Leptin: a multifunctional hormone}

\author{
HuAng Lu ${ }^{1}, \mathrm{CAI} \mathrm{Li}^{1,2, *}$ \\ ${ }^{1}$ Touc hstone Center for Diabetes Research \\ ${ }^{1}$ Departments of Physiology and, \\ ${ }^{2}$ Departments of Internal Medicine \\ The University of Texas Southwestern Medical Center \\ 5323 H. Hines Boulevard Dallas, TX 75390-8854, USA
}

\begin{abstract}
Leptin is the protein product encoded by the obese ( ob) gene. It is a circulating hormone produced primarily by the adipose tissue. ob/ob mice with mutations of the gene encoding leptin become morbidly obese, infertile, hyperphagic, hypothermic, and diabetic. Since the cloning of leptin in 1994, our knowledge in body weight regulation and the role played by leptin has increased substantially. We now know that leptin signals through its receptor, OB-R, which is a member of the cytokine receptor superfamily. Leptin serves as an adiposity signal to inform the brain the adipose tissue mass in a negative feedback loop regulating food intake and energy expenditure. Leptin also plays important roles in angiogenesis, immune function, fertility, and bone formation. Humans with mutations in the gene encoding leptin are also morbidly obese and respond to leptin treatment, demonstrating that enhancing or inhibiting leptin's activities in vivo may have potential therapeutic benefits.
\end{abstract}

Key words: Leptin, OB-R, hypothalamus, adipose tissue, obesity, diabetes, cytokine receptor.

Body weight regulation is a complex process that is rapidly becoming the center

\footnotetext{
* Correspondence author.

Tel: (214)-648-3340; Fax: (214)-648-9191; $\quad$ E-mail: li03@utsw.swmed.edu
} 
Leptin: a multifunctional hormone

of attention for public health experts in the industrialized world as well as developing countries[1]. In the United States alone, about half the adult population is considered overweight as defined by body mass index (BMI, ratio of body weight (kg) divided by the squared of the height $\left(\mathrm{m}^{2}\right)$ ) in excess of 25 . Of these individuals, half are clinically obese (with a BMI in excess of 30). A more disturbing trend is the increased early onset of obesity in children. This alarming trend has prompted the World Health Organization to declare obesity a worldwide epidemic.

Obesity is a public health challenge because it is associated with many complications, including type 2 diabetes, hypertension, coronary heart disease, and increased mortality rate[2]. Individuals diagnosed as clinically obese (BMI $>30)$ suffer a mortality rate about three times as high as persons with BMI of under 24.9. The added health care cost to treat obesity and associated complications in the United States alone amounts to an estimated $\$ 70$ billion per year. Additionally, $80 \%$ of obese individuals develop type 2 diabetes, which affect about $6 \%$ of the US population. Diabetes is a major cause of human suffering because of its many complications including blindness, kidney failure, amputations, and increased coronary artery disease and stroke. Effective method of weight reduction thus becomes an attractive strategy to prevent the onset of diabetes.

In recent years, several genes have been cloned that functions in the control of body weight. Of these, the adipose tissue derived hormone leptin has emerged as a central player[3]. It is a master regulator of boy weight; it is effective in lowering blood glucose and insulin level not only in diabetes due to obesity; it is also sufficient to reverse the severe diabetes due to congenital generalized lipodystrophy[4]. However, it is not understood how its action leads to increased insulin sensitivity and glucose utilization. Evidence is also accumulating that leptin functions to modulate a variety of important physiological processes, ranging from angiogenesis, immune function, fertility, to bone formation. This review briefly summarizes the known functions of leptin as a key regulator of body weight, its mechanism of signal transduction, and its functions in several important physiological processes.

\section{Leptin controls body weight and appetite via the hypothalamus}

Leptin has potent weight reducing effects in vivo. In ob/ ob mice, the gene encoding leptin is mutated, resulting in massive obesity[3]. Available data indicate that leptin functions as a key signal in a negative feedback loop regulating food intake and body weight.

The leptin receptor is a member of the cytokine receptor family[5]. Leptin' $\mathrm{s}$ effect on body weight and food intake is dependent on binding to the long form of the leptin receptor, $\mathrm{OB}-\mathrm{Rb}[6],[7]$. The OB- $\mathrm{Rb}$ form of the leptin receptor has an intracytoplasmic domain of 302 amino acids that includes several motifs for protein-protein interaction. The other forms of this receptor have short cytoplasmic regions (OB-Ra, 
c, d) or are secreted (OB-Re)[6].

A mutation that specifically ablates OB-Rb expression in $\mathrm{db}$ (diabetic) mice results in obesity and complete leptin resistance. OB- $\mathrm{Rb}$ is highly expressed in the hypothalamus as assayed by in situ hybridization and RNase protection analysis, suggesting that this brain region is an important site of leptin action[8],[9]. The importance of the hypothalamus as a target of leptin action is also suggested by the high potency of intrathecally administrated leptin and the fact that hypothalamic lesions lead to leptin resistance[10]. Ventromedial hypothalamus lesioned rats exhibit serum leptin concentrations that are four to five fold higher than sham operated controls within $24 \mathrm{~h}$ after surgery was performed[11]. Electrophysiological studies demonstrated that glucosereceptive neurons from the hypothalamus of lean but not Zucker diabetic fatty (ZDF) rats become inhibited (hyperpolarized) by leptin treatment. Such hyperpolarizationinduced inhibition was shown to be the result of leptin activation of an ATP-sensitive potassium channel[12]. These data are consistent with the hypothesis that leptin controls body weight and appetite via the hypothalamus[13]. Though the leptin receptor is expressed ubiquitously, its long form receptor is highly enriched in the hypothalamus. The neuronal circuits in the arcuate nucleus of hypothalamus that mediate leptingenerated signals involve NPY/AgRP neurons that increase food intake, and POMC/ CART neurons that inhibit food intake and energy metabolism[14].

\section{Leptin signals utilizing the Jak-STAT pathway}

Leptin receptors belong to the type I cytokine receptor family. Signal transduction by this family of receptors generally depends on ligand induced phosphorylation of soluble receptor tyrosine kinases such as JAK1, JAK2, JAK3, and Tyk2. These kinases in turn phosphorylate tyrosine residues on the receptor that serve as docking sites for SH2 domain containing proteins. Binding of proteins containing SH2 domains to the activated receptor and/or phosphorylation of such proteins initiates signal transduction[15].

Leptin activation of the Jak-STAT pathway was first analyzed using electrophoretic mobility shift assay (EMSA)[16]. In one such study, COS cells were transfected with the leptin receptor and different isoforms of STAT proteins. STAT DNA binding activities were assayed in the absence or presence of leptin using different probes that can bind to different STAT isoforms. This approach identified STAT3, -5 , and -6 as leptin activated factors. These findings were confirmed in other laboratories, and in some experiments, STAT1 was also activated[17],[18]. Because this is an in vitro system, the cell lines used ( $\mathrm{CHO}$ cells) may not express STATs and other accessory proteins as in OB-Rb positive cells in vivo. Therefore, further studies were performed to analyze STAT protein activation in tissue extracts from leptin-injected mice. When the same EMSA assay was repeated, it was found that STAT3 is the only member of this family that is activated by leptin, and such activation occurs only in the hypothalamus[16]. 
Leptin: a multifunctional hormone

Even though there is discrepancy between the in vitro and in vivo studies with regards to the nature of STAT proteins involved, these results establish that leptin signaling uses similar mechanism as other cytokine receptors and activates the Jak-STAT pathway.

Because there are four different JAK kinases known, JAK1, JAK2, JAK3, and Tyk2, it is necessary to determine if a unique Jak kinase or more than one Jak kinases are involved in leptin receptor signaling. To address this question, immunoprecipitation of leptin receptor and all Jak kinases was performed to study the Jak kinase that is capable of binding to the receptor. Two lines of evidence support that Jak2 is the Jak family of kinases that is activated by the leptin receptor. First, when cells were transfected with OB-R and immunoprecipitation of each Jak kinases was performed in the absence or presence of leptin, Jak2 was shown to be the only kinase that became tyrosine phosphorylated as a function of leptin addition. Tyrosine phosphorylation of the Jak kinases is associated with their activation. Second, when the leptin receptor was immunoprecipitated, Jak2 was the only Jak isoform that co-immunoprecipitated, although the binding was found to be constitutive[19]. Constitutive association of the Jak family kinase in the cytokine receptor has also been observed in other systems, such as in erythropoietin signaling[20]. These results confirm that Jak2 is the kinase component in the leptin receptor signal transduction pathway.

Like in other cytokine systems, phosphorylated tyrosines on the receptor become docking sites for downstream signaling molecules. These downstream molecules contain SH2 domains that recognize phosphorylated tyrosines as well as surrounding sequences of these phosphorylated tyrosine residues. In the case of the murine leptin receptor, there are three cytoplasmic tyrosines at amino acid positions 985,1077 , and 1138. Each is a potential phosphorylation site of the receptor activated Jak2 kinase. The identification of SH2 domain containing proteins activated by the leptin receptor is likely to have important implications for an understanding of the leptin signal transduction pathway and the molecular mechanisms that control body weight. In order to identify the components of the leptin signal transduction pathway, tyrosine phosphorylated cytoplasmic fragments of the leptin receptor were fused to GST and used as affinity reagents to isolate proteins that interact with the leptin receptor. In this fashion, SHP-2, a phosphotyrosine phosphatase, was isolated and found to bind Tyr 985 of the leptin receptor[21]. The biological significance of such association was also supported in other studies[22]. The STAT3 transcription factor was also found to bind to a phosphopeptide of OB-Rb spanning Tyr 1138. SHP-2 is tyrosine phosphorylated after leptin treatment of cells transfected with the leptin receptor. Tyrosine phosphorylation of SHP-2 was associated with decreased phosphorylation of JAK2 but not leptin receptor or STAT3 in vitro[21]. These data suggest that SHP-2 is a component of the leptin signal transduction pathway and may indicate that it attenuates leptin signaling by decreasing the level of phosphorylation of JAK2. 


\section{Leptin signaling occurs at peripheral tissues and may regulate many important physiological processes}

Northern blotting studies and RT-PCR experiments have demonstrated that all OB$\mathrm{R}$ isoforms, including OB-Rb, which is capable of signaling by itself, are expressed in extra-neural tissues[23]. This suggests that leptin signaling might also occur in these tissues and plays important functional roles, since leptin circulates in the bloodstream and can access most cell types within the body. Indeed the experiments performed using epithelial cells, endothelial cells, T cells, platelets, skin, and the pancreatic (cells showed that leptin signaling may be a critical step in the normal physiology of these cell types. These studies are summarized below.

\section{Leptin action in intestinal cells}

Leptin-mediated activation of the STAT pathway in vivo was first established in hypothalamus. Activation of this pathway was subsequently used as an assay to search for additional site of leptin action. Leptin receptor expression and in vivo signaling in discrete regions of the mouse gastrointestinal tract was detected. Expression of the functional leptin receptor isoform (OB- $\mathrm{Rb}$ ) is restricted to the jejunum and is readily detected by RT-PCR in isolated enterocytes from this site. Intravenous injection of leptin rapidly induced nuclear STAT5 DNA binding activity in jejunum of $+/+$ and obese ( ob/ob) mice but had no effect in the diabetic $(\mathrm{db} / \mathrm{db})$ mouse that lacks the functional OB-Rb isoform. In addition, an induction of the immediate-early gene c-fos is observed in jejunum in vivo. Leptin-mediated induction of a number of immediateearly genes and activation of STAT3 and STAT5 in a human model of small intestine epithelium, CACO-2 cells, corroborate this effect. Furthermore, intravenous leptin administration caused a significant 2-fold reduction in the apolipoprotein AIV transcript levels in jejunum 90 min after a fat load[24]. These results suggest that the epithelium of jejunum is a direct target of leptin action. Furthermore, this activity is dependent on the presence of OB-Rb. Lack of leptin or resistance to leptin action in this site is suggested to contribute to obesity and its related syndromes by directly affecting lipid handling.

\section{Leptin action in endothelial cells}

$\mathrm{OB}-\mathrm{Rb}$ is also expressed in human vasculature and in primary cultures of human endothelial cells. In vitro and in vivo assays revealed that leptin has angiogenic activity. In vivo, leptin induced neovascularization in corneas from normal rats but not in corneas from ZDF rats, which lack functional leptin receptors. These observations indicate that the vascular endothelium is a target for leptin and suggest a physiological mechanism whereby leptin-induced angiogenesis may facilitate increased energy expenditure[25].

Leptin action in platelets 
Leptin: a multifunctional hormone

OB-Rb was detected in platelets by Western blot analysis. Pretreatment of platelets with high concentrations of leptin $(100 \mathrm{ng} / \mathrm{ml}$, which is within the range of the concentration of circulating leptin in obese individuals) followed by addition of ADP induces platelet aggregation, while either alone was ineffective. This effect of leptin was suggested as a possible coupling factor between obesity and the cardiovascular disease associated with syndrome $\mathrm{X}$ and diabetes[26].

\section{Leptin action in $T$ cells}

Both ob/ob mice and db/db mice have impaired T-cell mediated immunity. Leptin was found to have a specific effect on T-lymphocyte responses, differentially regulating the proliferation of naive and memory $\mathrm{T}$ cells. It increased production of Th1 cytokines such as IFN- $\gamma$ and IL-2, but suppressed the production of TH2 cytokines such as IL4. TH1 cytokines have a proinflammatory function while TH2 cytokines have a regulatory function. This may explain the defective $\mathrm{T}$ cell immune responses in ob/ob and $\mathrm{db} / \mathrm{db}$ mice[27]. Leptin may thus serve to provide a link between nutritional status and cognate cellular immune function.

\section{Leptin action in skin cells}

Delayed wound healing is one of the many complications of diabetes. Leptin accelerates wound healing in ob/ob but not $\mathrm{db} / \mathrm{db}$ mice, suggesting that this effect is mediated by its receptor[28]. Interestingly, mice with a conditional knockout of STAT3, a component of the leptin receptor signal transduction pathway, from skin cells also results in delayed skin wound healing[29] . It needs to be confirmed if STAT3 indeed serves as a mediator of the wound healing response induced by leptin.

\section{Leptin action in hepatic cells}

The presence of OB-Rb in hepatic cells has been reported in some studies, using RTPCR, Northern blotting, and leptin binding assay[30]. Leptin treatment of these cells alters insulin sensitivity in these cells. In other studies, transfection of OB-Rb cDNA needs to be performed to demonstrate leptin signal transduction, which also affect insulin action in these cells[31]. Since liver is the major site of nutrient homeostasis, a direct leptin action in liver may modulate the body's response to excess food ingested in obesity.

\section{Leptin action in adipocytes}

Both RT-PCR and gel shift analysis demonstrated the presence of OB-Rb on adipocytes[32]. Mice exposed to chronic intravenous administration of leptin showed increased glucose utilization by its brown adipose tissue. White adipose tissue from lean rats but not ZDF rats showed an approximately 10 -fold increase in lipolysis when exposed to leptin ex vivo[32]. The same result was obtained when adipocytes were purified from these rats and treated with leptin[33]. These findings demonstrate that 
leptin may cause direct lipolysis.

\section{Leptin action in pancreatic $\beta$ cells}

Most work on leptin receptor signaling in peripheral tissues was performed using the pancreatic $\beta$ cell as a model. OB-Rb mRNA was detected in islets and pancreatic $b$ cells by both RT-PCR and northern blotting analysis[34],[35]. An inhibitory effect of leptin on insulin secretion was also detected. Using RINm5F cells and islets, a time dependent induction of STAT DNA binding activity was detected as a function of leptin treatment[36]. STAT3 tyrosine phosphorylation correlates very closely with the DNA binding activity as seen in the gel shift analysis. These results establish that leptin signaling is present in $\beta$ cells.

Most insight on the function of leptin signaling in pancreatic $\beta$ cells was obtained using islets from wild type Wistar rats and ZDF rats. The latter does not have a functional leptin receptor because of a point mutation at amino acid position 269 . This residue is changed from glutamine to proline and is located at the extracellular domain of the receptor[37-39]. It is not completely understood how a single amino acid mutation completely abolishes the function of OB-Rb, though there is evidence that such receptors do not translocate to plasma membrane as efficiently as wild type receptors, when expressed in heterologous systems[17],[40]. Islets from ZDF rats with such receptor point mutation are fat laden and become apoptotic as the diabetes progresses. Through adenovirus mediated OB-Rb gene transfer and treatment of virally infected islets with leptin, the diabetogenic phenotype of ZDF islets was completely normalized. This included restoration of glucose stimulated insulin secretion, reduced apoptosis, decreased intracellular triglyceride accumulation, and down-regulation of lipogenic enzymes[41-45]. These studies point to an essential function of leptin signaling in pancreatic $\beta$ cells.

\section{Signaling by the short form leptin receptor $O B-R a$}

It is generally believed that leptin signals only through the long form of its receptor, OB-Rb. This is because only OB-Rb contains motifs at its cytoplasmic domain that are capable of protein-protein interactions. However, a few studies using transfected cell lines have shown that a short leptin receptor isoform, OB-Ra, is also capable of signaling. When leptin is added to OB-Ra expressing cells, it is capable of inducing the expression of several immediate early genes such as c-fos, c-jun, and jun-B[46]; the mRNA level of these genes are increased by several fold after leptin stimulation of cells. Such induction of gene expression is mediated, at least in part, by the MAP kinases ERK1 and ERK2[47]. Most interestingly, OB-Ra is capable of inducing the tyrosine phosphorylation of Jak2 and IRS-1, suggesting that there might be a binding partner of OB-Ra that can mediate such response[48]. The nature of such a binding protein is not known, though OB-Rb does not seem to be the candidate. Several studies showed that OB-Ra and OB-Rb do not form heterodimers[49],[50], suggesting the existence of other pro- 
Leptin: a multifunctional hormone

teins that are involved in leptin signaling.

\section{A broader role for leptin}

In addition to the studies summarized above that used available assays to examine the activation of the leptin receptor signal transduction in central and peripheral tissues, several important physiological processes are also shown to be directly regulated by leptin, though the exact mechanisms involved remain to be elucidated.

\section{Leptin and fertility}

$\mathrm{ob} / \mathrm{ob}$ mice are infertile if not treated by leptin. When leptin was given to female ob/ ob animals, they can become pregnant and give birth to live pups with no apparent abnormalities in their phenotype[51]. Even in wild type mice, leptin also accelerates the maturation of the female reproductive tract and leads to an earlier onset of the oestrous cycle and reproductive function[52]. A parallel observation was also seen in humans where prepubertal surge of leptin was found to occur. These results broaden the roles played by leptin not only in body weight and appetite regulation, but also in the modulation of fertility.

\section{Leptin and IL-1 function}

Another intriguing observation of leptin function came from studies of knockout mice. It was found that leptin injection into IL-1RI knockout mice intracereboroventrically has no effect on food intake[53]. Because IL-1RI is responsible for all known functions of IL-1, it suggests that this receptor is responsible for the effects of leptin in the brain. This is also supported by the observation that central injection of IL-1 receptor antagonist inhibited the suppression of food intake caused by central or peripheral injection of leptin. Though a mechanistic explanation is lacking, it demonstrates that the interplay between leptin signaling and other endocrine pathways is crucial and remains to be elucidated in molecular detail.

\section{Leptin and bone formation}

Bone mass is regulated through bone remodeling. Bone remodeling involves two well-defined sequential steps: resorption of preexisting bone by the osteoblasts; de novo bone formation by the osteoblasts. If this balanced is disrupted, bone remodeling disease results. Osteoporosis is one of the most common diseases in the Western Hemisphere, occurring predominantly in postmenopausal women and aging men. Interestingly, it was observed by clinicians that obesity seems to protect from osteoporosis. This observation prompted researchers to look at bone formation in mouse models of obesity. Research performed with the use of ob/ ob and db/db mice demonstrated that leptin signaling deficiency also results in increased bone formation and bone density 
[54]. The effect of leptin on bone formation is probably mediated by the hypothalamus because intracerebroventricular infusion of leptin to ob/ob mice causes a decrease in bone density at a dose that does not have any effect on body weight. The possibility needs to be explored further whether pharmacological manipulation of the leptin pathway may be a novel approach to treat osteoporosis.

\section{Leptin and human physiology}

In humans, mutations of both leptin and the leptin receptor have been identified[5557]. As is the case in rodents, both mutations are recessive. Patients with homozygous mutations of both leptin and the leptin receptor are morbidly obese. While mice with $\mathrm{ob} / \mathrm{ob}$ and ob/ob mutations are phenotypically indistinguishable, human subjects with leptin receptor mutation exhibited significant growth retardation and central hypothyroidism, with reduced secretion of growth hormone and thyrotropin. These observations demonstrate that leptin action is also essential to maintain body weight in humans, with additional functions that are species specific.

\section{Perspectives}

Current data clearly demonstrate that leptin is a multifunctional hormone, playing important roles ranging from body weight regulation to fertility, insulin sensitivity, immune function, angiogenesis, even bone formation. Of particular importance in future research is the delineation of the complete signal transduction pathways used by leptin. An equally important area of research is the site of leptin action. Tissue specific knockout studies of the leptin receptor from peripheral tissues should shed light on the significance of direct leptin signaling in these tissues. Alternatively, a complementary approach may be pursued by restoring the function of $\mathrm{OB}-\mathrm{Rb}$ in a given tissue in a receptor deficient background ( $\mathrm{db} / \mathrm{db}$ ). Tissue specific promoter may be used to drive the expression of $\mathrm{OB}-\mathrm{Rb}$ in a transgenic mouse line. These can then be bred to $\mathrm{db} / \mathrm{db}$ mice so that OB-Rb expression is achieved only at a given tissue. Research in the next few years should provide answers to these interesting questions.

\section{ACKNOWLEDGMENTS}

Work in the authors' laboratory is supported by a start-up fund from the University of Texas Southwestern Medical Center, the Touchstone Center for Diabetes Research at UT Southwestern, Novo Nordisk A/S, and the Welch Foundation. C.L. is the recipient of a career development award from the American Diabetes Association. We thank our colleagues, Drs. C. B. Newgard and R. H. Unger, for thoughtful comments. 
Leptin: a multifunctional hormone

\section{REFERENCES}

[1] Kopelman PG. Obesity as a medical problem. Nature 2000; 404:635-43.

[2] Calle EE, Thun MJ, Petrelli JM, Rodriguez C, Heath CW, Jr. Body-mass index and mortality in a prospective cohort of U.S. adults. N Engl J Med 1999; 341:1097-105.

[3] Zhang Y, Proenca P, Maffei M, Barone M, Leopold L, Friedman JM. Positional cloning of the mouse obese gene and its human homologue. Nature 1994; 372:425-32.

[4] Shimomura I, Hammer RE, Ikemoto S, Brown MS, Goldstein JL. Leptin reverses insulin resistance and diabetes mellitus in mice with congenital lipodystrophy. Nature 1999; 401:73-6.

[5] Tartaglia LA, Dembski M, Weng X, et al. Identification and expression cloning of a leptin receptor, OBR. Cell 1995; 83:1263-71.

[6] Lee GH, Proenca R, Montez JM, et al. Abnormal splicing of the leptin receptor in diabetic mice. Nature 1996; 379:632-5. [7] Chen H, Charlat O, Tartaglia LA, et al. Evidence that the diabetes gene encodes the leptin receptor: Identification of a mutation in the leptin receptor gene in $\mathrm{db} / \mathrm{db}$ mice. Cell 1996; 84: 491-5.

[8] Mercer JG, Hoggard N, Williams LM, Lawrence CB, Hannah LT, Trayhurn P. Localization of leptin receptor mRNA and the long form splice variant $(\mathrm{Ob}-\mathrm{Rb})$ in mouse hypothalamus and adjacent brain regions by in situ hybridization. FEBS Letters 1996; 387:113-6.

[9] Ghilardi N, Ziegler S, Wiestner A, Stoffel R, Heim MH, Skoda R. Defective STAT signaling by the leptin receptor in diabetic mice. Proc Natl Acad Sci USA 1996; 93:6231-5.

[10] Halaas JL, Boozer C, Blair-West J, Fidahusein N, Denton D, Friedman JM. Physiological response to long-term peripheral and central leptin infusion in lean and obese mice. Proc Natl Acad Sci USA 1997; 94:8878-83.

[11] Suga A, Hirano T, Kageyama H, et al. Rapid increase in circulating leptin in ventromedial hypothalamus-lesioned rats: role of hyperinsulinemia and implication for upregulation mechanism. Diabetes 1999; 48:2034-8.

[12] Spanswick D, Smith MA, Groppi VE, Logan SD, Ashford ML. Leptin inhibits hypothalamic neurons by activation of ATP-sensitive potassium channels. Nature 1997; 390:521-5.

[13] Schwartz MW, Woods SC, Porte D Jr, Seeley RJ, Baskin DG. Central nervous system control of food intake. Nature 2000; 404:661-71.

[14] Friedman JM. Obesity in the new millennium. Nature 2000; 404:632-4.

[15] Darnell JE. STATs and gene regulation. Science 1997; 277:1630-5.

[16] Vaisse C, Halaas JL, Horvath CM, Darnell JE Jr, Stoffel M, Friedman JM. Leptin activation of Stat3 in the hypothalamus of wild-type and ob/ob mice but not db/db mice. Nature Genetics 1996; 14:95-7.

[17] Rosenblum CI, Tota M, Cully D, et al. Functional STAT 1 and 3 signaling by the leptin receptor (OBR); reduced expression of the rat fatty leptin receptor in transfected cells. Endocrinology 1996; 137: 5178-81.

[18] Baumann H, Morella KK, White DW, et al. The full-length leptin receptor has signaling capabilities of interleukin 6-type cytokine receptors. Proc Natl Acad Sci USA 1996; 93:8374-8.

[19] Ghilardi N, Skoda RC. The leptin receptor activates Janus kinase 2 and signals for proliferation In a factor-dependent cell line. Mol Endocrinology 1997; 11:393-99.

[20] Witthuhn BA, Quelle FW, Silvennoinen O, et al. JAK2 associates with the erythropoietin receptor and is tyrosine phosphorylated and activated following stimulation with erythropoietin. Cell 1993; 74: 227-36.

[21] Li C, Friedman JM. Leptin receptor activation of SH2 domain containing protein tyrosine phosphatase 2 modulates Ob receptor signal transduction. Proc Natl Acad Sci USA 1999; 96:9677-82.

[22] Carpenter LR, Farruggella TJ, Symes A, Karow ML, Yancopoulos GD, Stahl N. Enhancing leptin response by preventing SH2- containing phosphatase 2 interaction with Ob receptor. Proc Natl Acad Sci USA 1998; 95:6061-6. 
[23] Fei H, Okano HJ, Li C, et al. Anatomic localization of alternatively spliced leptin receptors (Ob-R) in mouse brain and other tissues. Proc Natl Acad Sci USA 1997; 94:7001-5.

[24] Morton NM, Emilsson V, Liu YL, Cawthorne MA. Leptin action in intestinal cells. J Biol Chem 1998; 273:26194-201.

[25] Sierra-Honigmann MR, Nath AK, Murakami C, et al. Biological action of leptin as an angiogenic factor. Science 1998; 281:1683-6.

[26] Nakata M, Yada T, Soejima N, Maruyama I. Leptin promotes aggregation of human platelets via the long form of its receptor. Diabetes 1999; 48:426-9.

[27] Lord GM, Matarese G, Howard JK, Baker RJ, Bloom SR, Lechler RI. Leptin modulates the T-cell immune response and reverses starvation-induced immunosuppression. Nature 1998; 394:897-901.

[28] Ring BD, Scully S, Davis CR, et al. Systemically and topically administered leptin both accelerate wound healing in diabetic ob/ ob mice. Endocrinology 2000; 141:446-9.

[29] Sano S, Itami S, Takeda K, et al. Keratinocyte-specific ablation of Stat3 exhibits impaired skin remodeling, but does not affect skin morphogenesis. EMBO J 1999; 18:4657-68.

[30] Cohen B, Novick D, Rubinstein M. Modulation of insulin activities by leptin. Science 1996; 274:11858.

[31] Wang Y, Kuropatwinski KK, White DW, et al. Leptin receptor action in hepatic cells. J Biol Chem 1997; 272:16216-23.

[32] Siegrist-Kaiser CA, Pauli V, Juge-Aubry CE, et al. Direct effects of leptin on brown and white adipose tissue. J Clin Invest 1997; 100:2858-64.

[33] Wang MY, Lee Y, Unger RH. Novel form of lipolysis induced by leptin. J Biol Chem 1999; 274:175414.

[34] Kieffer TJ, Heller RS, Habener JF. Leptin receptors expressed on pancreatic beta-cells. Biochem Biophys Res Commun 1996; 224:522-7.

[35] Emilsson V, Liu YL, Cawthorne MA, Morton NM, Davenport M. Expression of the functional leptin receptor mRNA in pancreatic islets and direct inhibitory action of leptin on insulin secretion. Diabetes 1997; 46:313-6.

[36] Morton NM, Emilsson V de, Groot P, Pallett AL, Cawthorne MA. Leptin signalling in pancreatic islets and clonal insulin-secreting cells. J Mol Endocrinol 1999; 22:173-84.

[37] Phillips MS, Liu Q, Hammond HA, et al. Leptin receptor missense mutation in the fatty Zucker rat. Nature Genetics 1996; 13:18-9.

[38] Chua SC, Jr White, DW Wu-Peng, XS Liu, SM Okada N, Leibel RL. Phenotype of fatty due to Gln269pro mutation in the leptin receptor (Lepr). Diabetes 1996; 45:1141-3.

[39] Iida M, Murakami T, Ishida K, Mizuno A, Kuwajima M, Shima K. Substitution at codon 269 (glutamine $\rightarrow$ proline) of the leptin receptor (OB-R) cDNA is the only mutation found in the Zucker fatty (fa/fa) rat. Biochem Biophys Res Commun 1996; 224:597-604.

[40] Crouse JA, Elliott GE, Burgess TL, et al. Altered cell surface expression and signaling of leptin receptors containing the fatty mutation. J Biol Chem 1998; 273:18365-73.

[41] Koyama K, Chen G, Wang MY, et al. beta-cell function in normal rats made chronically hyperleptinemic by adenovirus-leptin gene therapy. Diabetes 1997; 46:1276-80.

[42] Wang MY, Koyama K, Shimabukuro M, Newgard CB, Unger RH. OB-Rb gene transfer to leptinresistant islets reverses diabetogenic phenotype. Proc Natl Acad Sci USA 1998; 95:714-8.

[43] Shimabukuro M, Wang MY, Zhou YT, Newgard CB, Unger RH. Protection against lipoapoptosis of beta cells through leptin-dependent maintenance of Bcl-2 expression. Proc Natl Acad Sci USA 1998; 95:9558-61.

[44] Wang MY, Koyama K, Shimabukuro M, Mangelsdorf D, Newgard CB, Unger RH. Overexpression of leptin receptors in pancreatic islets of Zucker diabetic fatty rats restores GLUT-2, glucokinase, and glucose-stimulated insulin secretion. Proc Natl Acad Sci USA 1998; 95:11921-6.

[45] Unger RH, Zhou YT, Orci L. Regulation of fatty acid homeostasis in cells: novel role of leptin. Proc 


\section{Leptin: a multifunctional hormone}

Natl Acad Sci USA 1999; 96:2327-32.

[46] Murakami T, Yamashita T, Iida M, Kuwajima M, Shima K. A short form of leptin receptor performs signal transduction. Biochem Biophys Res Commun 1997; 231:26-9.

[47] Yamashita T, Murakami T, Otani S, Kuwajima M, Shima K. Leptin receptor signal transduction: OBRa and OBRb of fa type. Biochem Biophys Res Commun 1998; 246:752-9.

[48] Bjorbaek C, Uotani S, da Silva B, Flier JS. Divergent signaling capacities of the long and short isoforms of the leptin receptor. J Biol Chem 1997; 272:32686-95.

[49] DeVos R, Guisez Y, Van der Heyden J, et al. Ligand-independent dimerization of the extracellular domain of the leptin receptor and determination of the stoichiometry of leptin binding. J Biol Chem 1997; 272:18304-10.

[50] White DW, Kuropatwinski KK, Devos R, Baumann H, Tartaglia, LA. Leptin receptor (OB-R) signaling. Cytoplasmic domain mutational analysis and evidence for receptor homo-oligomerization. J Biol Chem 1997; 272:4065-71.

[51] Chehab FF, Lim ME, Lu R. Correction of the sterility defect in homozygous obese female mice by treatment with the human recombinant leptin. Nature Genetics 1996; 12:318-20.

[52] Chehab FF, Mounzih K, Lu R, Lim ME. Early onset of reproductive function in normal female mice treated with leptin. Science 1997; 275:88-90.

[53] Luheshi GN, Gardner JD, Rushforth DA, Loudon AS, Rothwell NJ. Leptin actions on food intake and body temperature are mediated by IL-1. Proc Natl Acad Sci USA 1999; 96:7047-52.

[54] Ducy P, Amling M, Takeda S, et al. Leptin inhibits bone formation through a hypothalamic relay: a central control of bone mass. Cell 2000; 100:197-207.

[55] Strobel A, Camoin TIL, Ozata M, Strosberg AD. A leptin missense mutation associated with hypogonadism and morbid obesity. Nature Genetics 1998; 18:213-5.

[56] Montague CT, Farooqi IS, Whitehead JP, et al. Congenital leptin deficiency is associated with severe early-onset obesity in humans. Nature 1997; 387:903-8.

[57] Clement K, Vaisse C, Lahlou N, et al. A mutation in the human leptin receptor gene causes obesity and pituitary dysfunction. Nature 1998; 392:398-401. 